\title{
Successfully Reducing Rates of Cesarean Delivery
}

\author{
Micbael E. Jobansen, MD, MS, Associate Editor $r_{i}$ Christal M. Clemens
}

Ann Fam Med 2021;19(3):iii. https://doi.org/10.1370/afm.2699.

T The Annals of Family Medicine encourages readers to develop a learning community to improve health care and health through enhanced primary care. Participate by conducting a journal club. We encourage diverse participants to think critically about important issues affecting primary care and act on those discussions. ${ }^{1}$

\section{HOW IT WORKS}

In each issue, the Annals selects an article and provides discussion tips and questions. Join our online discussion. (Open the article, click on the e-Letters tab, and submit a comment.) Discussion questions and information are online at: www.AnnFamMed.org/content/AJC.

\section{CURRENT SELECTION}

White VanGompel EC, Perez SL, Datta A, et al. Culture that facilitates change: a mixed-methods study of hospitals engaged in reducing cesarean deliveries. Ann Fam Med. 2021;19(3):249-257.

\section{Discussion Tips}

Many institutions have worked to decrease the rate of cesarean deliveries in order to decrease complications of childbirth. Some of these complications include increased risk of bleeding, infection, longer healing times, risk for thromboembolism, and complications in future pregnancies. Additionally, cesarean births impose greater costs on hospitals and the health care system. This study used mixed methods to compare hospitals that were successful at lowering the caesarian delivery rate to those that were less successful in order to understand why certain systems might have been more successful at lowering rates than others.

\section{Discussion Questions}

- What questions are asked and why do they matter?

- What are mixed methods studies? Why are they not more common in the medical literature?

- What is a consolidated framework for implementation research?

- How does this study advance beyond previous research and clinical practice on this topic?
- How strong is the design for answering the question? o What are the benefits and weaknesses of mixed methods studies (compared to purely qualitative or quantitative studies)?

o What is the Labor Culture Survey?² What is this designed to measure?

o What are the strengths and weaknesses of the qualitative sampling?

- To what degree can the findings be accounted for by: o How were hospitals selected, excluded, or lost to follow-up?

o How the main outcome variables were measured?

o How the qualitative interviews were analyzed?

- What are the main study findings?

- How comparable is the study sample to your hospital? What is your judgment about the transportability of the findings?

o How might hospitals address some of the barriers to integrating best practices regarding cesarean vs natural birth?

o Do you think patients are educated sufficiently regarding the risks and benefits of vaginal births cesarean birth? Do you think this target would alter cesarean rates in your hospital?

-What contextual factors are important for interpreting the findings?

o How would you gauge the potential benefits and harms of the interventions in this space?

- How might this study change your practice? Education? Research?

- Who the constituencies are for the findings, and how they might be engaged in interpreting or using the findings?

- What are the next steps in interpreting or applying the findings?

- What researchable questions remain?

\section{References}

1. Stange KC, Miller WL, McLellan LA, et al. Annals Journal Club: It's time to get RADICAL. Ann Fam Med. 2006;4(3):196-197. https:// www.annfammed.org/content/4/3/196

2. White VanGompel E, Perez S, Wang C, Datta A, Cape V, Main E. Measuring labor and delivery unit culture and clinicians' attitudes toward birth: revision and validation of the Labor Culture Survey. Birth. 2019;46(2):300-310. 